\title{
Comunicação e educação: os movimentos do pêndulo
}

\section{Communication and education: the movements of the pendulum}

\author{
Adilson Odair Citelli \\ Escola de Comunicações e Artes da Universidade de São Paulo (ECA-USP) São Paulo, SP, Brasil. \\ ORCID: 0000-0002-0838-9917 \\ <citelli@uol.com.br>
}

\author{
Como citar este artigo (How to cite this article): \\ CITELLI, Adilson Odair. Comunicação e educação: os movimentos do pêndulo. Revista Famecos, Porto Alegre, v. \\ 25 , n. 3, p. 1-15, setembro, outubro, novembro e dezembro de 2018: ID29914. \\ DOI: http://dx.doi.org/10.15448/1980-3729.2018.3.29914.
}

\section{RESUMO}

Este artigo resulta de pesquisa em escolas localizadas na cidade de São Paulo e entorno e se vincula a preocupações concernentes às interfaces educomunicativas. Um dos objetivos do trabalho foi o de verificar como os meios de comunicação e suas linguagens entram em circulação no cotidiano das aulas. Daí decorreram perguntas afeitas aos eventuais usos da comunicação nos processos de ensino e aprendizagem, assim como o reconhecimento dos hábitos midiáticos de discentes e docentes. Entre as técnicas investigativas acionaram-se entrevistas, questionários, observação direta, abrangendo cento e noventa e sete docentes e seiscentos e noventa e nove discentes, distribuídos em trinta e duas escolas. Os resultados indicam existir desencontros entre os ritmos dos discursos escolares e as temporalidades que matizam o cotidiano de alunos e professores, marcadas fortemente pelos media. Propomos promover a inter-relação comunicativo-educativa enquanto possibilidade de circundar aquelas distonias.

\section{ABSTRACT}

This article is the result of a research study that took place in schools located in the city of São Paulo and surroundings, developed around the concept of educommunication and its interfaces. One of the goals was to verify how the media and their languages come into circulation in the daily classes. This led to questions about possible uses of communication in both teaching and learning processes, as well as the identification of media habits of students and teachers. In regards to investigative techniques, we used interviews, surveys and direct observation, covering one hundred and ninety-seven teachers and six hundred and ninety-nine students, distributed in thirty-two schools. Results indicate that mismatches exist between the rhythms of school discourses and the temporalities that make up the daily life - intensely pervaded by media - of students and teachers. We propose promoting a communicative-educational interrelation as a possibility to go around such dystonia.

Keywords: Communication. Education. Sociotechnical.

\section{Introdução}

É crescente o interesse acadêmico e mesmo de setores governamentais e da sociedade civil dirigido ao melhor entendimento dos vínculos entre comunicação e educação. As maneiras de encaminhar e mesmo designar a interface apresenta diferenças resultantes, muitas vezes, de perspectivas distintas no plano conceitual ou da luta para delimitar espaços no debate 
intelectual, segundo esclarecido por Pierre Bourdieu ao tratar dos mecanismos que orientam as disputas pelo poder no interior do campo científico.

Encontramos na tradição anglo-saxônica designadores à maneira deMedia Literacy, Media Education, Digital Literacy in Education, Education in Media Literacy; na França Competénce Mediatique, Éducation aux Médias; na Itália, Educazione ai Media; na América espanhola e Espanha: Educación en Medios, Educación para la Comunicación; no Brasil, Educomídia, Pedagogia da Comunicação, Educação Midiática, Comunicação e Educação, Literacia Digital, Educomunicação. E isto para mencionar alguns enunciados que, malgrado conterem perspectivas nem sempre convergentes, se dirigem a uma área comum de interesses teóricos, de pesquisa e intervenção social, que acumula relevante produção bibliográfica, exemplos de ações junto aos sistemas comunicativos e educativos, afora estar presente em cursos de graduação, especialização e pós-graduação.

O neologismo Educomunicação vem sendo utilizado no Brasil e em países da América Latina, ao menos desde os finais dos anos 1980, sendo divulgado por documentos da UNESCO (2009) - que o associam, de forma um pouco restrita, ao âmbito da Media Education, vale dizer, da educação para os meios de comunicação. Os delimitadores históricos pregressos que ensejam o aparecimento deste vetor de estudos e das suas formas de nomeação podem ser encontrados, em nosso continente, desde os anos 1960, ganhando intensidade e abrangência como resposta aos regimes ditatórios que assolarão o Cone Sul' . Naquela conjuntura de violenta repressão e proibições, acionar estratégias para fazer circular a informação e o conhecimento não censurados exigiu dos grupos populares, das comunidades eclesiais de base, dos educadores, artistas e intelectuais pactuados com a democracia, o incremento de ações comunicativoeducativas capazes de fraturar o círculo de ferro forjado pelos militares e seus acólitos civis.

É compreensível que os movimentos de resistência ao estado de exceção - cuja amplitude metonímica alcançava quase todos os países da América Latina -, fossem desdobrados em inúmeros empreendimentos postos sob insígnias (atribuídas ou autonomeadas) de imprensa alternativa, escola libertadora, teatro do oprimido, música de protesto, e, last but not least, leitura crítica dos meios de comunicação. Em várias unidades escolares, particularmente as de recorte experimental ou vocacional, foram estruturados programas visando a facultar debates entre os discentes a partir das mensagens postas em circulação pelos media, tendo em vista entender as manobras discursivas que velavam

1 O largo movimento preocupado em trazer a comunicação para o âmbito educativo foi gestado nas primeiras décadas do século XX, como atestam, no Brasil, a obra de Edgard Roquette-Pinto e Anísio Teixeira. Para reflexão mais ampla sobre o assunto, consultar: Citelli $(2004,2011)$; Soares (2011). 
o que deveria ser desvelado. E mesmo a efetivação de procedimentos que ensinassem como elaborar produtos de comunicação à maneira de jornais, revistas, roteiros de rádio e televisão, em exercícios voltados a mostrar como é possível esclarecer ou sonegar determinados campos de sentidos, algo não muito distante do learning by doing, o aprender fazendo, propugnado por John Dewey. De algum modo, estava em causa educar para a comunicação e mesmo não perder de vista os compromissos da comunicação com a educação (aspecto, ademais, regrado pela Constituição de 1988), conforme o artigo 221: "A produção e a programação das emissoras de rádio e televisão deverá atender os seguintes princípios: I - preferência a finalidades educativas, artísticas, culturais e informativas (...)". Como sabemos, o texto legal é solenemente ignorado.

Naquele contexto e decorrente dele, Mario Kaplún cunhou o termo Educomunicação. Ao educador-comunicador de origem argentina, mas que morou em vários países da América Latina, sendo, inclusive, um dos fundadores da Escola de Ciências da Comunicação, da Universidad de la República, no Uruguai, é atribuído o uso preliminar do neologismo. De qualquer maneira, ao fundir em vocábulo único duas áreas do conhecimento há muito assentadas, educação e comunicação, e postas sob larga clivagem analítica, com tradições teóricas, metodológicas e de pesquisa, fica a ideia da recorrência entre instâncias social e academicamente relevantes: já não é possível falar em educação ignorando os fenômenos comunicacionais, do mesmo modo a comunicação responsável não pode descurar dos permanentes desafios educativos, estejam eles posicionados nos planos formais, não formais ou informais.

O fato é que várias instituições vêm empregando o vocábulo resultando na sua "dicionarização" e consequente ampliação de uso, em movimentos que incluem a busca de legitimação, conforme consigna Pierre Bourdieu (2007). E servem como exemplos: a Escola de Comunicações e Artes-USP, que criou uma licenciatura em Educomunicação; a Universidade Federal de Campina Grande, mantenedora do bacharelado em Educomunicação; a Editora Paulinas, que possui coleção de livros cujo título geral é Educomunicação; a Editora Editus (Universidade Estadual de Santa Cruz - Bahia) com a série Comunicação e Educação, a revista Comunicação \& Educação, voltada ao enfoque educomunicativo; os vários programas de pós-graduação ${ }^{2}$ em âmbito nacional e internacional que destacam a palavra chave ora em evidência; a Associação Brasileira de Pesquisadores e Profissionais em Educomunicação (ABPEducom).

2 Consulta ao banco de teses da CAPES, feita em 17 de janeiro de 2017, mostrava a existência de 213 dissertações e teses abarcando o termo em tela, na maioria dos casos ensejando o título do trabalho e em outros dando a ele peso especial, distribuídos por programas de Comunicação e de Educação, mas também de outras áreas do grupo de Ciências Humanas e Sociais. 
Daí muitos estudiosos afirmarem que a Educomunicação deve ser vista como campo emergente. Aqui não pretendemos avançar reflexão sistemática sobre o sintagma "campo emergente" dado que sobre ele pairam indagações de natureza epistemológica, metodológica, de procedimentos de pesquisa, cuja necessidade de amadurecimento e aprofundamento necessitam ser enfrentados, segundo indica, entre outros, Cláudio Messias (2017), mas apenas consignar a crescente utilização de certo termo/designativo/conceito dentro e fora dos circuitos estritamente acadêmicos.

Cabe apontar que existem, inclusive, políticas públicas como a Lei no 13.941, de 29 de dezembro de 2004, instituidora no município de São Paulo do Programa EDUCOM: Educomunicação pelas onda do rádio; o Mais Educação, que abre espaço entre as suas dez áreas de atividades opcionais para as escolas desejosas de participarem do Programa Ensino Médio Inovador, introduzindo o "macro campo educomunicação"; a própria Lei de Diretrizes e Bases da Educação Nacional (LDB), que proclama a necessidade de se pensar as relações comunicação/educação. Há, igualmente, o trabalho de ONGs como a Viração e Cidade Escola Aprendiz, em São Paulo, Comunicação e Cultura no Ceará, todas, de alguma maneira, utilizando e praticando ideias que animam a Educomunicação, em seus propósitos básicos de promover processos comunicativo-educativos apoiados em relações dialógicas, colaborativas, voltados à formação cidadã.

\section{Andamentos}

O debate que destaca o papel das interfaces educomunicativas no entendimento das maneiras como a informação e o conhecimento se organizam e circulam em nossa quadra histórica está vinculado aos arranjos sociotécnicos incidentes, sobretudo, nos processos de comunicação. Ou, como enuncia Rubim (2009):

A expansão quantitativa da comunicação, em especial em sua modalidade midiatizada; a diversidade das novas modalidades de mídias presentes no espectro societário (...); o papel desempenhado pela comunicação midiatizada como modo (crescente e até majoritário) de experenciar e conhecer a vida, a realidade e o mundo; a presença e abrangência das culturas midiáticas como circuito cultural hegemônico, que organiza e difunde socialmente comportamentos, percepções, sentimentos, ideários, valores, etc.; as ressonâncias sociais da comunicação midiatizada sobre a produção da significação (intelectiva) e da sensibilidade (afetiva), sociais e individuais; a prevalência da mídia como esfera de publicização (hegemônica) dentre os diferenciados"espaços públicos"socialmente existentes, articulados e concorrentes; as mutações espaciais e temporais provocadas pelas redes midiáticas, na perspectiva de forjar 
uma vida planetária e em tempo real; o crescimento vertiginoso dos setores voltados para a produção, circulação e difusão e consumo de bens simbólicos; a ampliação (percentual) dos trabalhadores da informação e da produção simbólica no conjunto da população economicamente ativa e o aumento crescente das despesas com as comunicações, em suas diferenciadas modalidades (Rubim, 2009, p. 105 e 106).

Há certo consenso ensejando a ideia de que a midiatização, ao recortar grupos, classes, gêneros, idades, etnias, malgrado as especificidades de cada segmento e as divergências de interesses entre eles, assim como a maneira de os meios de comunicação representá-los, termina por trazer consigo discursos, mensagens, arranjos sígnicos, dos quais fica difícil manter equidistância. Alguns autores chegam mesmo a falar que pela importância dos processos de midiatização, é imperioso ter em vista a construção das bases de uma cidadania comunicativa (Mata, 2006). Posto de outro modo: a participação mais ampla dos sujeitos no debate público se tornou bastante dependente do acesso - e de algum domínio -, aos mediadores técnicos da comunicação. Sem isto, as disputas discursivas e os jogos de poder restam esmaecidos ou encobertos, comprometendo, por último, a própria ideia da cidadania (em sentido republicano, no qual política e comunicação não se distanciam). Explicase, neste contexto, a existência de propostas que desejam incluir no ensino formal e mesmo não formal disciplinas ou mesmo programas de qualificação/ capacitação sob o título de: "educação para a mídia", "literacia midiática”, "leitura crítica da comunicação", etc. Permaneçamos com Maria Cristina Mata (2006, p. $146)^{3}$ :

As regulações comunicativas vigentes em determinada sociedade, as lógicas informativas predominantes, os recursos tecnológicos disponíveis para diferentes setores sociais, as modalidades de organização social e política devem ser levadas em conta como condições objetivas para o exercício da cidadania comunicativa. Mas

3 "Las regulaciones comunicativas vigentes en una sociedad determinada, las lógicas informativas predominantes, los recursos tecnológicos disponibles para diferentes sectores sociales, las modalidades de organización social y política deben ser tenidas en cuenta como condiciones objetivas para el ejercicio de la ciudadanía comunicativa. Pero existen múltiples condiciones subjetivas que deberemos interrogar a fin de no simplificar nuestros análisis. Los modos de imaginarse como sujetos de derecho propios de diferentes individuos y colectivos sociales, sus maneras de vincularse con quienes detentan la legalidad y legitimidad social para expresarse y producir normas al respecto, las representaciones hegemónicas y contrahegemónicas acerca de lo que significa comunicarse y comunicar hoy, en sociedades mediatizadas, las expectativas depositadas en las instituciones, los medios, las propias fuerzas expresivas, son dimensiones ineludibles para comprender hasta dónde y en qué condiciones la indefensión o la impotencia de los públicos es una condición irreversible o no para reivindicar el derecho a informarse, a expresarse, a ampliar el espacio público con múltiples palavras". (2006, p. 146) 
existem múltiplas condições subjetivas que teremos que interrogar para não simplificar nossas análises. Os modos de se imaginar como sujeitos de direito próprios a diferentes indivíduos e grupos sociais, suas maneiras de se relacionar com aqueles que possuem legalidade e legitimidade social para expressar-se e produzir normas a esse respeito, as representações hegemônicas e contra-hegemônicas sobre o que significa comunicar-se e comunicar hoje nas sociedades midiatizadas, as expectativas depositadas nas instituições, nos media, nas próprias forças expressivas, são dimensões inevitáveis para entender até que ponto e em que condições o desamparo ou a impotência dos públicos é uma condição irreversível ou não para reivindicar o direito a se informar, a se expressar, a ampliar o espaço público com múltiplas palavras. Cristina Mata (2006, p. 146):

É relevante observar que o problema geral da cidadania comunicativa ocorre frente ao reconhecimento de estarmos mergulhados em determinado cenário histórico. E nele os componentes sociotécnicos e tecnoculturais são incorporados às dinâmicas de vida dos sujeitos, podendo traduzir-se, por exemplo, em ambiências comunicativas capazes de redefinir as funções e os lugares ocupados pela recepção. As mudanças advindas na esteira das tecnologias digitais abriram possibilidades de os sujeitos atuarem nos territórios da produção dos signos, das elaborações simbólicas e representacionais, assim como da própria circulação das mensagens. Enfim, retomamos a ideia chave que nos acompanha e segundo a qual a comunicação passou a desempenhar, em nosso tempo, papel central, abrangendo desde o cotidiano da vida associada, entrando na elaboração das narrativas, seguindo por trocas discursivas, indo às influências sobre as sociabilidades, percorrendo camadas de significados que velam, revelam ou desvelam - conforme cada caso e situação - as artimanhas do real. E mais, no regime de midiatização fica o desafio de expandir a cidadania comunicativa pondo-a em estreito contato com o mundo da educação, destacadamente aquela manifesta nas salas de aula. Neste reenquadramento é oportuno mirar para as reflexões e práticas que estão sendo ativadas pelas interfaces educomunicativas.

De certo modo, e ao menos sob o ponto de vista legal, existe preocupação dos educadores para reconhecer o lugar da comunicação no sistema escolar. É o que indica a resolução no 3 do Conselho de Educação Básica (CEB), de 26/06/1998, no artigo 10, ao firmar a organização curricular do Ensino Médio em torno de áreas do conhecimento. Uma delas, dedicada às Linguagens, Códigos e suas Tecnologias, é desdobrada em objetivos dos quais destacamos alguns do nosso interesse: 
- Entender os princípios das tecnologias da comunicação e da informação, associá-las aos conhecimentos científicos, às linguagens que lhes dão suporte e aos problemas que se propõem solucionar;

- Entender a natureza das tecnologias da informação como integração de diferentes meios de comunicação, linguagens e códigos, bem como a função integradora que elas exercem na sua relação com as demais tecnologias;

- Entender o impacto das tecnologias da comunicação e da informação na sua vida, nos processos de produção, no desenvolvimento do conhecimento e na vida social;

- Aplicar as tecnologias da comunicação e da informação na escola, no trabalho e em outros contextos relevantes para sua vida.

Os pontos elencados, a despeito de conhecerem elaboração há vinte anos, pediam que fosse incluído no cotidiano das salas de aula o tema da comunicação, aliás, em sentido abrangente, haja vista dizer respeito a variáveis sistêmicas e processuais: compreender a natureza e princípios; analisar os veículos; trabalhar com as diferentes linguagens, signos e códigos; apreender os alcances sociais e históricos; etc. Neste passo, cabe um acréscimo. Em 16/02/2017 foi sancionada a que vem sendo chamada de reforma do Ensino Médio. Afora outros elementos componentes do diploma legal, tratou ele, fundamentalmente, da estrutura curricular, constituída em torno de cinco áreas eletivas: I - linguagens e suas tecnologias; II - matemática e suas tecnologias; III - ciências da natureza e suas tecnologias; IV - ciências humanas e sociais aplicadas; V - formação técnica e profissional. Os conteúdos correspondentes às respectivas áreas dependem, entretanto, do que advirá da Base Nacional Comum Curricular (BNCC). Naquilo que nos é relevante, manifestado nos objetivos acima, não parece difícil verificar a ocorrência de junções entre o enunciado na resolução CEB e o que se apresenta seja na reforma do ensino médio seja na BNCC do ensino fundamental e vigente em Estados como o de São Paulo, quando advém o tema da comunicação nos ambientes escolares. Enfim, os documentos oficiais reconhecem ser inescusável tratar das interfaces educomunicativas na educação formal. A se ponderar, contudo, que entre a manifestação prescritiva e o cotidiano das salas de aula existem distonias deixando o sistema escolar em compasso de espera e a manter práticas didático-pedagógicas pouco acertadas com as demandas da cidadania comunicativa.

Em pesquisa por nós concluída em $2017^{4}$, a partir de coleta realizada entre 2014 e 2015, relativa aos circuitos media-escolas-tecnologias, envolvendo docentes e discentes do nível básico de trinta e duas escolas espalhadas pelas

4 Trabalho feito com o apoio do CNPq. Relatório final de posse do Autor. 
zonas norte, sul e oeste da cidade de São Paulo, afora alguns municípios localizados em raio de duzentos quilômetros da capital, e referenciada no resumo deste texto, verificou-se que os professores entrevistados têm clareza sobre a importância da comunicação, entendida em seus aspectos amplos, para as atividades tocantes à educação formal. Acerca deste ponto, vejamos um dos quadros que organizam a tabulação dos nossos dados:

\section{Tabela 1 - Você considera a inter-relação escola e meios de comunicação?}

\begin{tabular}{|l|l|l|}
\hline Antagônica & 4 & $2 \%$ \\
\hline Complementar e antagônica & 5 & $3 \%$ \\
\hline Complementar & 158 & $95 \%$ \\
\hline Total de respondentes & \multicolumn{2}{|c|}{167} \\
\hline
\end{tabular}

Fonte: $\mathrm{O}$ autor

A maioria dos professores aponta a existência de continuidades entre os discursos didático-pedagógicos e as linguagens advindas de instituições não escolares. Dentre as incorporações facultadas pelos media arrolam-se notícias saídas em jornais e rádios, programas televisivos, e que permitem abrir espaços para tratar de assuntos como: migrações, refugiados, violência urbana, mercado, esporte, crise política, desemprego, etc. Encontram-se, ademais, referências à análise crítica dos veículos e suas mensagens, à realização de blogs, ao envolvimento de alunos na utilização dos celulares para filmagens e montagens de materiais a serem socializados nas salas de aula. No decorrer da nossa pesquisa acompanhamos várias destas atividades e exercícios quando das observações procedidas nas escolas. Tal assertiva pede, contudo, matizes a fim de se afastar conclusões e generalizações pouco ajustadas à realidade do ensino brasileiro de nível básico.

O fato de emergir maior consciência do lugar ocupado pelas interfaces comunicativo-educativas, segundo já acentuado, não significa a existência de fluxos entre os verbos constatar e agir. Para a consecução desta travessia existe muito a ser feito, máxime no tangente à formação continuada dos professores frente aos reptos postos à escola básica na sociedade midiatizada. Em nossa investigação formulamos perguntas dirigidas ao tema da capacitação profissional docente e boa parte das respostas convergiam para o item que registrava as dificuldades relativas ao trabalho em sala de aula quando se tratava de ativar as inúmeras possibilidades abertas pela comunicação. Desta sorte, ao mesmo tempo em que ocorre o reconhecimento do papel dos media, da ampla digitalização, da força da internet, revelam-se, também, inseguranças para dar 
sequência ao assunto incorporando-o aos projetos político-pedagógicos das unidades educativas formais. $E$ uma destas incertezas resulta do fato de que a maioria dos professores não tratou, durante a licenciatura, da comunicação, tendo em mira os aspectos atinentes às linguagens complexas, ao jogo dos signos, aos cruzamentos de códigos, ou mesmo aos elementos propriamente técnicos, industriais, mercadológicos. Ademais, é alto o número de docentes em exercício que revela sequer conhecer cursos que possam mais bem capacitá-los na área em tela, conforme aponta a tabela abaixo:

Tabela 2 - Você tem informação acerca de algum programa oficial voltado à formação permanente do professor para a área dos meios de comunicação ou das novas tecnologias?

\begin{tabular}{|l|l|l|}
\hline Sim & 49 & $26,8 \%$ \\
\hline Não & 138 & $73,2 \%$ \\
\hline Total de respondentes & \multicolumn{2}{|c|}{187} \\
\hline
\end{tabular}

Fonte: O Autor

A escola registra intercorrências que recortam os comentários feitos nos parágrafos anteriores; ali identificamos uma delas, concernente às relações educomunicativas, objeto último de nossas preocupações. Malgrado furtemonos a exame detido da estrutura funcional do sistema educacional brasileiro, sobretudo aquele voltado à escola pública de nível básico, é importante acentuar uns poucos elementos dele componentes e cuja presença no cotidiano das salas de aula ajudam a situar o tema sobre a qual nos debruçamos.

As grandes cidades do nosso país, em particular, são atravessadas por inúmeras vicissitudes: insulamento dos grupos e classes sociais; óbices à mobilidade urbana; adensamento e disseminação das várias formas de violência; frustrações advindas dos impedimentos à cultura, ao lazer, à arte; esperanças que se esvaem nos imperativos reificados do trabalho precário. Nestas vertentes, alinham-se algumas das modulações que são carreadas para o espaço escolar e onde encontramos docentes cujo reconhecimento social e valorização econômica do seu ofício parecem perdidos no cruzamento de alguma grande avenida, assim como discentes à busca de propósitos capazes de justificar as suas presenças, por horas, diante de uma lousa preenchida com matérias cujos significados nem sempre recebem esclarecimentos.

Tratando-se de quadro complexo o seu enfrentamento costuma vir acompanhado de artimanhas e respostas evasivas, sendo mais fácil, por evidente, a difusão regular de números que comprovariam o tamanho do nosso 
fracasso educacional. É como se a pretensa positividade matemática encarnada em tabelas e porcentagens servisse para disseminar assombro, reiterar o óbvio e deixar o problema seguir sem maiores percalços. Daí a divulgação regular dos vários tipos de exames que avaliam o desempenho dos alunos, disciplinas, séries, escolas, etc., de que servem como exemplos: Sistema de Avaliação da Educação Básica (SAEB); Exame Nacional do Ensino Médio (ENEM); Sistema de Avaliação do Rendimento Escolar do Estado de São Paulo (SARESP); Programa Internacional de Avaliação de Alunos (PISA); Provinha Brasil. O resultado de tais indicadores serve para intensificar o burburinho, mormente através dos media, voltado a deixar claro que perdemos o bonde da história. O noticiário amplifica, por alguns dias, informações desalentadoras. Seguem alguns exemplos. $O$ Ministério de Educação e Cultura (MEC) divulgou, em 2017, comunicado dizendo que na Avaliação Nacional de Alfabetização (ANA), mais da metade dos discentes do terceiro ano do ensino fundamental apresentavam insuficiências em leitura e matemática. Pouco antes, em 2014, o mesmo Ministério apontava que 56,17\% dos alunos não registravam proficiência leitora - ou seja, capacidade de localizar informações explícitas ou mesmo recolher o sentido geral do que era lido -; o índice teve pequeno decréscimo em 2017, atingindo $54,73 \%$, sendo que no tópico da escrita, $34 \%$ dos discentes não conseguiam escrever palavras ou dotar os seus textos de inteligibilidade. Recentemente, os meios de comunicação destacaram briefing do MEC cientificando que na prova do ENEM a nota 0 (zero) em redação conheceu progressos, passando de 291.806 candidatos em 2016, para 309.157 , em 2017, numa oscilação de $4.8 \%$ para $6.5 \%$. Aproximadamente 4.5 milhões de candidatos prestam o exame anual do ENEM. E o Brasil, pelos números do PISA de 2015, ocupava a 63a posição em ciências, 59a em leitura e 66ª em matemática, tenho em vista os 72 países avaliados.

Deixemos de lado outros indicadores, haja vista apenas percorrerem o caminho pouco frutuoso da redundância. Frente a cada rodada de resultados das avaliações do nosso ensino básico, os canais de televisão, as estações de rádio, as páginas dos jornais e revistas, a algaravia das redes sociais, abrem temporada para os indignados de ocasião, os oportunistas de várias tonalidades, os editoriais enviesados, filtrarem espanto oferecendo, em contrapartida, poções mágicas aptas a alterarem o cenário das misérias educacionais que nos afligem. Os remédios receitados à cura para tais males são de largo espectro: combate duro ao chamado corporativismo (i.e. sindicalismo, "grevismo", descompromisso com o interesse público, etc.); pagamento dos profissionais da educação por cumprimento de metas (ou o dispêndio sob forma de bônus que não se incorporam aos salários, portanto, deixando de fazer parte dos cálculos para efeito de aposentadoria); implantação dos padrões qualitativos criados 
pela Organização Mundial do Comércio (OMC); adoção da aula cronometrada, dispositivo de controle a partir do qual o professor deve dividir o assunto do dia em minutos a serem cumpridos entre a explicação, a discussão, a avaliação, etc., esdrúxulo do qual, felizmente, restam poucos defensores. Leguemos para outra circunstância o tratamento acerca da imantação de todos os paradoxos anteriores e concentrados na autointitulada Escola sem partido. Como se verifica, o tratamento consistente dos nossos desafios educacionais permanece abrigado sob uma retórica posta a meio caminho entre o espetáculo e o populismo neoliberal.

Deixa de ser tarefa simples investir na busca de projetos educacionais comprometidos com a qualidade, segundo espírito republicano, laico, inovador, em condições de enfrentar os incitamentos do mundo presente. $O$ fato de acentuarmos, neste contexto, o papel da comunicação, sobretudo, junto às escolas, discentes e docentes, apenas esclarece a existência de um vetor que requisita intensificar o movimento cujo norte não deve ficar sob o domínio da "sinfonia dos pasmados" - expressão do receituário liberal-conservador, muitas vezes a esconder o interesse, por exemplo, de reprovar, desqualificar, o ensino público e enlevar o privado -, mas que, ao contrário, possibilite estruturar um programa de trabalho apto a introduzir novas alternativas à educação formal. $E$, dentre elas, encontra-se o reconhecimento das singularidades hodiernas voltadas a produzir, circular e acessar a informação e o conhecimento.

É preciso não perder de vista que a escola continua exercitando modelos de ensino e aprendizagem calcados no enciclopedismo, na acumulação informativa, na aula pouca dada ao exercício dialógico. A despeito dos avanços ocorridos neste território, haja vista as propostas construtivistas, as metodologias baseadas no ensino por projeto, a orientação educativa, as contribuições de educadores como Paulo Freire, etc., o quadro geral pouco se afasta dos mecanismos de ajustamento vigente há longo tempo nas salas de aula. É curioso observar que tal arquitetura pouco responde, mesmo a certas exigências impostas, hoje, pelo capital em sua busca por mão de obra, ao menos em parte, qualificada. O mundo do trabalho vem se organizando de outras maneiras e das quais seguem alguns exemplos: desregulamentação, "pejotização", "o empresário de si mesmo" (Dardot e Laval, 2016), "precariado" (Braga, 2005), etc.; novas solicitações quanto às competências profissionais - o jornal Folha de S. Paulo (2017), a partir de relatório publicado pela consultoria McKinsey, informa que no Brasil, até 2030, 15.7 milhões de trabalhadores serão afetados pela automação. Entretanto, a despeito do dramatismo deste cenário, no qual sobreleva-se a quebra de direitos sociais e trabalhistas, o ensino público continua em sua compassada rota de fornecer o mínimo aos discentes. Seria 
possível ponderar acerca de inúmeros problemas envolvendo os circuitos entre educação formal, estoque de mão de obra e exigências do capital, mas como não reside em nosso escopo, no momento, análise amiúde sobre tal âmbito, basta lembrar que a escola em curso, guardadas as exceções tanto na área pública como privada, acaba dando sequência a um projeto que aumenta a exclusão social, haja vista, limitar-se, praticamente, a garantir certo nível de aprendizado em algumas disciplinas.

Posicionar o debate nos termos de uma ressignificação da escola implica ter no horizonte estratégias que se afastem do conhecimento regulado discutido por Boaventura Sousa Santos (2000), portanto da adaptação excludente imposta, hoje, pelo ensino instrumental. É sob tal perspectiva que entendemos a pertinência de estreitar os vínculos comunicativo-educativos nas salas de aula, procedimento, em última instância, ocupado em divisar as profundas mudanças culturais, sociais, tecnológicas que envolvem os "ecossistemas escolares". A compreensão das passagens entre os discursos propedêuticos, escolarizados, e os não escolares, isto é aqueles produzidos em outras instituições, a exemplo dos media, pode não apenas franquear a revisão dos componentes curriculares das unidades educativas formais, atualizando-os e dinamizando-os, como também permitir a leitura analítica e crítica da própria comunicação - tendente a ser confundida com as chamadas tecnologias educativas, com o exercício errático da pesquisa em enciclopédias digitais, com a frequência a blogs e sites dados como fontes de informação validadas in limine.

De toda sorte, os cruzamentos entre educação, circunstâncias culturais e comunicação, tanto ocorrem como se requisitam, a despeito de nem sempre ficarem explícitos ou serem tratados em suas injunções. É o que pensa, por exemplo, Raymond Williams, em vários dos seus escritos, ao insistir na aproximação entre os campos comunicativos (um complexo de linguagens, métodos de trabalho, formas de organização, etc.) e educativos. E propugna que os docentes e demais envolvidos na administração e gestão escolar, muitas vezes marcados por preconceito contra as novas formas de disponibilizar informação e conhecimento, e os profissionais comunicadores busquem associações e diálogos que terminem por enriquecer o cotidiano dos espaços escolares (Williams,1961).

O autor inglês acrescenta - em direção do que poderíamos chamar, nos dias correntes, de literacia midiática, alfabetização midiática, alfabetização para os meios de comunicação, leitura crítica da comunicação, educomunicação, etc. a importância de existir um aprendizado dos mecanismos regentes dos sistemas 
de comunicação. Tal estratégia permitiria a "perda de ingenuidade"5 do público quanto ao disposto socialmente pelos diferentes veículos comunicacionais. Em atualização histórica, esta proposta nos colocaria, também, frente aos dispositivos móveis, à internet, às redes sociais, etc., tão presentes no cotidiano de professores e alunos.

Passados quase cinquenta anos dos escritos de Raymond Willians que animaram os nossos comentários, e entendendo as nuances nas quais aquelas enunciações foram constituídas, permanecemos frente ao mesmo incitamento de posicionar a comunicação e a educação em ambiência convergente.

\section{Enfim}

Neste texto procuramos mostrar como a educação formal está sendo desafiada a promover mudanças em suas concepções e práticas, haja vista a existência de uma nova quadra histórica na qual despontam, ao menos, três grandes fenômenos, aqui retomados a título de síntese: as dinâmicas tecnoculturais e de convergência comunicacional; a percepção de um tempo socialmente acelerado; as singularidades do sensório. Vale dizer, ganha extensão um procedimento no qual os sujeitos redefinem com maior celeridade os seus lugares sociais, seus modos de ver e perceber o mundo, em boa medida acionando os dispositivos da comunicação. É compreensível, portanto, que os chamados saberes escolares, ainda demais ajustados às lógicas do ensino propedêutico, segundo identificamos em nossa citada pesquisa, estejam diante de instigações que, por um lado, trazem desassossego e, por outro, convidam a pensar em alternativas e novos formatos para encaminhar os fazeres educativos.

Intentamos argumentar que as mudanças esperadas não devem atingir apenas superficialmente o cotidiano das salas de aula, a exemplo dos pequenos acertos nos conteúdos disciplinares e na formatação das "grades" curriculares, ou mesmo no uso de alguns "recursos" comunicacionais para facilitar o entendimento de tópicos programáticos, dado estar em jogo, agora, um amplo rearranjo cultural, social, tecnológica, entrelaçado à elaboração, organização, distribuição e descodificação do conhecimento e da informação. É forçoso considerar, portanto, que os projetos voltados a constituir outras relações nas escolas, nos mecanismos de ensino e aprendizagem, nos modos de tratar a sociabilidade dos jovens, não podem se fazer à revelia da comunicação, haja vista o lugar estratégico que ela ocupa em nossa quadra histórica.

5 "loss of naivety" (Williams, 1969, p. 132) 


\section{Referências}

BOURDIEU, Pierre. O mercado de bens simbólicos. In: MICELI, Sérgio (org.). A economia das trocas simbólicas. São Paulo: Perspectiva, 2007.

BRAGA, Ruy. A política do precariado. Do populismo à hegemonia lulista. São Paulo: Boitempo, 2012.

CITELLI, Adilson. Comunicação e educação. A linguagem em movimento. São Paulo, SENAC, 2004.

. Ensino à distância na perspectiva dos diálogos com a comunicação. Revista Comunicação, mídia e consumo. São Paulo, v. 8, n. 22, p. 187-209, jul. 2011.

DARDOT, Pierre e LAVAL, Christian. A nova razão do mundo. Ensaio sobre a sociedade neoliberal. São Paulo: Boitempo, 2016.

FOLHA DE S.PAULO. Automação vai mudar a carreira de brasileiros até 2030. São Paulo, 21. jan, 2017, p. A17.

MATA, Maria Cristina. Comunicación y ciudadanía. Problemas teórico-políticos de su articulación. Revista Fronteiras. São Leopoldo, v. 8, n. 1, p. 5-15, jan.abr. 2006.

MESSIAS, Cláudio. A audiência protagonista e os pressupostos da Educomunicação: reflexões epistemológicas. In: NAGAMINI, Eliana e GOMES, Ana Luisa Zaniboni (Orgs.). Dinâmicas e suportes para conhecer, reconhecer e integrar saberes em Comunicação e Educação. v.4. Ilhéus, Editus, 2017.

RUBIM, Antonio Albino Canelas. Políticas culturais e novos desafios. MATRIZes, v. 2, n. 2, p. 93-115, jun. 2009.

SANTOS, Boaventura de Sousa. A crítica da razão indolente. Contra o desperdício da experiência. São Paulo: Cortez, 2000.

SOARES, Ismar de Oliveira. Educomunicação: o conceito, o profissional, a aplicação. São Paulo: Paulinas, 2011.

UNESCO: Youth engaging with the world: media, communication and Social change. UNESCO: Nordicom/Sweden, 2009.

WILLIAMS, Raymond. The long revolution. London and New York: Columbia University Press, 1961.

Communication. London: Penguin Books, 1969. 
Recebido em: 14/02/2018

Aceito em: 08/04/2018

Dados do autor:

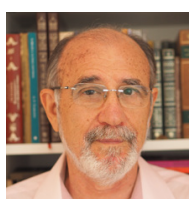

Adilson Odair Citelli | citelli@uol.com.br

Escola de Comunicações e Artes da Universidade de São Paulo (ECA-USP).

Doutor e Mestre em Literatura Brasileira pela Universidade de São Paulo (USP). Prof. titular da Escola de Comunicações e Artes da Universidade de São Paulo (ECA-USP). É docente, sob regime RDIDP, dos Programas de Graduação e Pós-Graduação da ECA-USP e pesquisador 1B do CNPq.

Endereço do autor:

Escola de Comunicação e Artes - Universidade de São Paulo (ECA-USP)

Av. Professor Lúcio Martins Rodrigues, 443

Cidade Universitária

05.508-020 - São Paulo/SP 